\title{
Empirical use of fluoroquinolones improves the survival of critically ill patients with tuberculosis mimicking severe pneumonia
}

\author{
Yu-Tzu Tseng ${ }^{1}$, Yu-Chung Chuang ${ }^{2}$, Chin-Chung Shu', Chien-Ching Hung ${ }^{2}$, Chiung-Fang Hsu² and \\ Jann-Yuan Wang $2^{2 *}$
}

\begin{abstract}
Introduction: Empirical use of fluoroquinolones may delay the initiation of appropriate therapy for tuberculosis (TB). This study aimed to evaluate the impact of empirical fluoroquinolone use on the survival of patients with pulmonary TB that mimicked severe community-acquired pneumonia (CAP) requiring intensive care.

Methods: Patients aged $>18$ years with culture-confirmed pulmonary TB who presented as severe CAP and were admitted to the ICU were divided into fluoroquinolone (FQ) and nonfluoroquinolone (non-FQ) groups based on the type of empirical antibiotics used. Those patients with previous anti-TB treatment or those who died within 3 days of hospitalization were excluded. The primary end point was 100-day survival.

Results: Of the 77 patients identified, 43 (56\%) were in the FQ group and 34 (44\%) were in the non-FQ group. The two groups had no statistically significant difference in co-morbidities ( $95 \%$ vs. $97 \%, P>0.99)$ and Acute Physiology and Chronic Health Evaluation (APACHE) II scores (21.2 \pm 7.1 vs. $22.5 \pm 7.5, P=0.46$ ) on ICU admission. Overall, $91 \%$ and $82 \%$ of patients in the FQ and non-FQ groups, respectively, had sputum examinations for TB within 1 week of admission $(P=0.46)$, and results were positive in $7 \%$ and $15 \%(P=0.47)$, respectively. For both groups, 29\% received appropriate anti-TB therapy within 2 weeks after ICU admission. The 100-day mortality rate was $40 \%$ and $68 \%$ for the FQ and non-FQ groups, respectively $(P=0.02)$. By Cox regression analysis, APACHE score $<20$, no bacteremia during the ICU stay, and empirical fluoroquinolone use were independently associated with survival.
\end{abstract}

Conclusion: Empirical use of fluoroquinolones may improve the survival of ICU patients admitted for pulmonary TB mimicking severe CAP.

\section{Introduction}

Severe community-acquired pneumonia (CAP), defined as pneumonia acquired in the community area that rapidly progresses to require ICU admission, is a major infectious cause of hospitalization and mortality [1]. In patients presenting with severe CAP, fluoroquinolones (FQs) have been recommended as first-line empiric antibiotic therapy due to their broad-spectrum antimicrobial effect [2]. The use of FQs has been proven to reduce the length of hospital stay and is more cost-effective

\footnotetext{
* Correspondence: jywang@ntu.edu.tw

${ }^{2}$ Department of Internal Medicine, National Taiwan University Hospital and National Taiwan University College of Medicine, No. 7, Chung Shan S. Road, Zhongzheng District, Taipei City 10002, Taiwan

Full list of author information is available at the end of the article
}

than using the combination therapy of $\beta$-lactams plus macrolides [3,4].

In endemic areas of tuberculosis (TB), the clinical manifestations of pulmonary $\mathrm{TB}$ are highly variable and may even mimic CAP [5,6]. Although FQs have excellent in vitro and in vivo bactericidal activity against Mycobacterium tuberculosis [7-9], empirical use of FQ monotherapy for CAP has raised concerns regarding delays in the initiation of appropriate anti-TB therapy, an increase in mortality and the emergence of drug resistance [10-13]. However, several other studies do not corroborate these findings [14-18]. In different TB endemic areas, it is difficult to define the relationship between the duration of FQ exposure and the development of resistance to FQ. 
Addressing the effects of different FQs on delays or resistance is also difficult, which may explain the contradictory results.

In patients with pulmonary $\mathrm{TB}$ requiring intensive care, the mortality rate approaches 50\% [19]. Among the deaths, about $50 \%$ occur within 26 days and $75 \%$ within 75 days after ICU admission [20]. Previous studies have demonstrated that the survival of patients with TB can be significantly improved if anti-TB therapy is started within 14 days of hospitalization [11,21,22]. Whether empirical use of FQ in critically ill patients can improve survival or can cause delays in the diagnosis of TB and increase mortality remains unclear.

This retrospective study aimed to investigate the impact of empirical FQ use on the survival of patients with pulmonary $\mathrm{TB}$ manifesting as severe $\mathrm{CAP}$ requiring intensive care, in a TB endemic area.

\section{Materials and methods Study subjects}

This retrospective study was conducted at the National Taiwan University Hospital, a tertiary-care referral center in Taiwan, where the 2008 incidence and mortality rate of TB was 62 and 3.3 per 100,000 population, respectively [23]. The database of the mycobacteriology laboratory and ICU records was searched to identify TB patients between January 2005 and December 2010. The inclusion criteria were age ${ }^{3} 18$ years, culture-confirmed pulmonary $\mathrm{TB}$, radiographic findings suggestive of severe CAP that rapidly progressed and required intensive care within 1 week of hospitalization, and no previous anti-TB therapy except FQs prior to ICU admission.

CAP was defined as pneumonia that developed outside the hospital setting, with classic symptoms of fever, cough and dyspnea, laboratory findings of leukocytosis, leucopenia or elevated serum C-reactive protein, and radiographic findings of pulmonary consolidation. The first-line anti-TB agents included isoniazid, rifampin, ethambutol, pyrazinamide, and streptomycin. Acid-fast smears and mycobacterial cultures of sputum and other respiratory specimens were performed as described previously [24]. Indications for ICU admission included respiratory failure or septic shock.

The identified patients were divided into two groups: patients who received empiric FQ therapy (that is, levofloxacin, moxifloxacin, and ciprofloxacin) before pulmonary TB was confirmed by culture (FQ group); and those who received antibiotics other than FQs (non-FQ group). The hospital's Research Ethics Committee approved the study (NCT registration number 9561707008). Informed consent was waived.

\section{Data collection}

All of the medical records for the enrolled patients were reviewed. Respiratory symptoms were defined as cough, dyspnea, and hemoptysis. Gastrointestinal symptoms were defined as nausea, vomiting, gastrointestinal bleeding, or diarrhea. Steroid use was defined as use of $>10$ mg prednisolone daily during hospitalization [25]. Chest images were independently reviewed by two pulmonologists. If a discrepancy was noted between their interpretations, the image was further reviewed by a third pulmonologist who was blinded to the results.

Bacteremia in the ICU was defined as positive blood cultures obtained during the ICU stay, with the exclusion of contaminated culture results (for example, only one in two sets of blood cultures that reported Bacillus or coagulasenegative staphylococci). The Acute Physiology and Chronic Health Evaluation (APACHE) II score and the Sequential Organ Failure Assessment score within the first 24 hours of ICU admission were used to evaluate disease severity and organ dysfunction [26,27]. Patients who received immunosuppressants, anti-cancer chemotherapy, radiation, and steroids [25], or had another disease that was sufficiently advanced to suppress resistance to infection (for example, leukemia, lymphoma, or acquired immunodeficiency syndrome), were defined as immunocompromised hosts. The primary end point was 100-day survival.

\section{Statistical analysis}

Inter-group difference was calculated using the independent-samples $t$ test for continuous variables and the chisquare test or Fisher's exact test for categorical variables, as appropriate. Time-to-event curves were generated by the Kaplan-Meier method and compared using the logrank test. Cox proportional hazards regression analysis was performed to identify prognostic factors for 100-day survival after ICU admission. The potential factors included age, sex, empirical FQ use, immunocompromised status, APACHE score ( ${ }^{3} 20$ vs. $\left.<20\right)$ [28], Sequential Organ Failure Assessment score $\left({ }^{3} 8\right.$ vs. <8) [29], albumin level ( $<3$ vs. ${ }^{3} 3$ ) [30], bacteremia during ICU stay, performance of acid-fast smears and mycobacterial cultures of respiratory specimens within 1 week of ICU admission, grading of acid-fast smears, and initiation of anti-TB therapy within 2 weeks of ICU admission. Significance levels for entry into the stepwise variable selection procedure were set at 0.15 . Two-sided $P<0.05$ was considered significant. All statistical analyses were performed using SPSS version 18.0 (SPSS Inc., Chicago, IL, USA).

\section{Results}

Between January 2005 and December 2010, 1,928 patients with culture-confirmed pulmonary $\mathrm{TB}$ were 
identified. Among these, 184 patients (9.5\%) were admitted to the ICU during their hospital stay, including 77 (4.0\%) who presented as severe CAP that resulted in respiratory failure or septic shock, and were enrolled for this study. Of the 107 patients who were excluded, 61 (33.2\%) were suspected of having $\mathrm{TB}$ and received antiTB therapy before their ICU admission, 29 (15.8\%) had no airway symptoms on presentation, 13 (7.1\%) had been hospitalized for more than 1 week before the ICU admission, three (1.6\%) died within 3 days after the ICU admission, and one (0.5\%) had no sufficient medical information.

Of the 77 patients presenting severe CAP, empirical FQs were given to 43 patients before the date of diagnosis of culture-confirmed pulmonary TB (FQ group), including 30 patients who received levofloxacin, seven ciprofloxacin, and seven moxifloxacin (one patient received more than one FQ during hospitalization). All of these 43 patients took FQs for more than 3 days (range, 3 to 155 days; mean duration FQ intake, 9.5 days). Of the seven patients who received ciprofloxacin, the FQ was started when a diagnosis of nosocomial infection was made more than 3 days after admission. All patients in the FQ and non-FQ groups received other $\beta$-lactam antibiotics before their ICU stay, including amoxicillin/clavulanic acid in $11.6 \%$ and $14.7 \%(P=$ 0.74 ), respectively, ampicillin/sulbactam in $20.9 \%$ and $35.3 \%(P=0.20)$, respectively, anti-pseudomonal antibiotics in $53.5 \%$ and $61.8 \%(P=0.50)$, respectively, and linezolid in $2.3 \%$ and $0 \%(P>0.99)$, respectively.

All except one patient (98\%) in the FQ group had undergone investigations for other respiratory pathogens, which included urine antigen tests for Legionella, serology tests for Mycoplasma pneumoniae, and nasal swab for influenza. One patient tested positive for influenza and another had concurrent pneumococcal pneumonia with bacteremia that caused respiratory failure. In the non-FQ group, $62 \%$ had undergone studies for other respiratory pathogens and only one tested positive for Mycoplasma IgM.

Based on the clinical characteristics of the FQ and non-FQ groups (Table 1), there were no statistically significant differences in age, sex, co-morbidities, APACHE score, Sequential Organ Failure Assessment score, and radiographic findings between the two groups. The HIV sero-status was available in 34 patients, including two in the non-FQ group who were sero-positive for HIV. Of the other 43 patients with unknown HIV sero-status, none had AIDS-defining opportunistic illnesses except TB during follow-up [31]. More patients in the FQ group had fever as the initial symptom than in the nonFQ group (63\% vs. $35 \%, P=0.02)$. Mean serum albumin levels were $<3 \mathrm{~g} / \mathrm{dl}$ in both groups. Five patients in each group did not need intubation on ICU admission and all five in the FQ group survived, while two patients (40\%) in the non-FQ group died.

There were no statistically significant differences between the two groups in the proportion of patients who underwent sputum TB examination within 1 week and those who started anti-TB therapy within 2 weeks of ICU admission (Table 2). However, more patients in the non-FQ group than in the FQ group died before anti-TB therapy was started $(27 \%$ vs. $9 \%, P=0.05)$. Among the 39 patients (91\%) who received anti-TB therapy in the FQ group, 16 continued to receive FQ for $>7$ days together with anti-TB therapy.

For the FQ and non-FQ groups, the interval between start of investigations for pulmonary TB and the start of anti-TB therapy were $20.9 \pm 14.7$ and $16.8 \pm 18.0$ days $(P=0.32)$, respectively. The interval between hospital admission to initiation of anti-TB therapy was $24.1 \pm$ 15.6 and $24.7 \pm 17.2$ days $(P=0.89)$, respectively. The lengths of ICU stay $(30.0 \pm 20.5$ days vs. $17.5 \pm 17.9$ days, $P<0.01)$ and hospitalization $(71.2 \pm 62.7$ days vs. $38.4 \pm 25.5$ days, $P<0.01)$ were significantly longer in the FQ group than in the non-FQ group.

Anti-TB susceptibility tests for the 77 isolates of $M$. tuberculosis revealed resistance to streptomycin in two cases and one case each to ethambutol co-resistance to isoniazid and ethambutol, co-resistance to isoniazid and streptomycin, and triple-resistance toisoniazid, rifampin plus ethambutol. None of the isolates were resistant to ofloxacin. Follow-up sputum samples were collected in all of the 77 patients, and $26(33.8 \%)$ were culture positive for $M$. tuberculosis, including 15 in the FQ group. Of the 26 isolates, anti-TB susceptibility testing was repeated in 10, including four in the FQ group. The susceptibility patterns of the 10 follow-up isolates were identical to those of their corresponding initial isolates.

Forty patients (52\%) died within 100 days of ICU admission, including 17 (39.5\%) in the FQ group and 23 (67.6\%) in the non-FQ group. Twenty-three patients (57.5\%) died during their ICU stay, while 17 (42.5\%) died after their transfer out of the ICU. The cause of death was pneumonia in 26 patients (65\%) and hypercapnic respiratory failure, ischemic bowel disease, acute respiratory distress syndrome with shock, sepsis with profound shock, disseminated TB confirmed by bone marrow and urine sample cultures, and multi-drugresistant Acinetobacter baumannii empyema in one patient each. Another eight patients died after hospital discharge. Their deaths were judged to be attributed to TB by the Taiwan Center for Disease Control.

The survival patterns of patients in the FQ and non-FQ groups are shown in Figure 1. By Cox regression analysis, APACHE score ${ }^{3} 20$ (hazards ratio $=3.75$; $95 \%$ confidence interval $=1.34$ to 10.44 ), bacteremia in the ICU (hazards ratio $=3.88 ; 95 \%$ confidence interval $=1.64$ to 9.19 ), and 


\begin{tabular}{|c|c|c|c|}
\hline & Fluoroquinolone $(n=43)$ & Nonfluoroquinolone $(n=34)$ & $P$ value \\
\hline Age (years) & $72.9 \pm 12.4$ & $76.2 \pm 14.5$ & 0.28 \\
\hline Male & $33(77)$ & $26(77)$ & 0.99 \\
\hline Underlying diseases & $41(95)$ & $33(97)$ & $>0.99$ \\
\hline Diabetes mellitus & $12(28)$ & $6(18)$ & 0.29 \\
\hline COPD & $5(12)$ & $9(27)$ & 0.09 \\
\hline Malignancy & $8(19)$ & $5(15)$ & 0.65 \\
\hline Autoimmune disease & $2(5)$ & $1(3)$ & 0.7 \\
\hline Liver cirrhosis & $2(5)$ & $0(0)$ & \\
\hline HIV & $0(0)$ & $2(6)$ & \\
\hline \multicolumn{4}{|l|}{ Initial symptoms } \\
\hline Respiratory symptoms & $40(93)$ & $32(94)$ & $>0.99$ \\
\hline Fever & $27(63)$ & $12(35)$ & 0.02 \\
\hline Consciousness disturbance & $11(26)$ & $4(12)$ & 0.13 \\
\hline APACHE score & $21.2 \pm 7.1$ & $22.5 \pm 7.5$ & 0.46 \\
\hline Arterial pH & $7.4 \pm 0.1$ & $7.4 \pm 0.1$ & 0.19 \\
\hline Serum sodium & $136.6 \pm 6.7$ & $135.0 \pm 8.5$ & 0.35 \\
\hline Serum potassium & $3.9 \pm 0.8$ & $4.1 \pm 0.7$ & 0.26 \\
\hline Serum creatinine & $1.8 \pm 1.7$ & $1.9 \pm 1.8$ & 0.87 \\
\hline Hematocrit & $32.5 \pm 6.8$ & $32.6 \pm 5.6$ & 0.93 \\
\hline Leukocyte count $\left(10^{3} / \mu \mathrm{l}\right)$ & $13.9 \pm 8.5$ & $12.8 \pm 7.2$ & 0.53 \\
\hline $\mathrm{FiO}_{2}{ }^{3} 50 \%$ & $32(74)$ & $20(59)$ & 0.22 \\
\hline Albumin $(g / d l)$ & $2.7 \pm 0.5$ & $2.8 \pm 0.5$ & 0.29 \\
\hline Bacteremia in ICU & $5(12)$ & $6(18)$ & $>0.99$ \\
\hline SOFA score & $8.0 \pm 3.6$ & $7.3 \pm 3.9$ & 0.47 \\
\hline \multicolumn{4}{|l|}{ Radiographic findings } \\
\hline Bilateral involvement & $34(79)$ & $27(79)$ & $>0.99$ \\
\hline Cavitation & $3(7)$ & $0(0)$ & 0.25 \\
\hline Miliary & $1(2)$ & $1(3)$ & $>0.99$ \\
\hline Pleural effusion & $21(49)$ & $21(62)$ & 0.36 \\
\hline Smear-positive for acid-fast bacilli & $3(7)$ & $5(15)$ & 0.47 \\
\hline Steroid use & $21(49)$ & $19(56)$ & 0.65 \\
\hline Undergone bronchoscopy & $5(12)$ & $5(15)$ & 0.95 \\
\hline
\end{tabular}

Data presented as $n$ (\%) or mean \pm standard deviation. APACHE, Acute Physiology and Chronic Health Evaluation score; COPD, chronic obstructive pulmonary

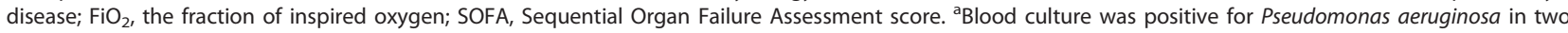
patients, Acinetobacter baumannii in two patients, and for Proteus spp., Enterobacter spp., Escherichia coli, Klebsiella pneumoniae, Streptococcus pneumoniae, Staphylococcus haemolyticus, Corynebacterium spp., Burkholderia cepacia, Candida parapsilosis, and Fusobacterium nucleatum in one patient each. Two patients had more than one pathogen.

empiric use of FQ (hazards ratio $=0.36$; $95 \%$ confidence interval $=0.17$ to 0.77 ) were independently associated with 100-day survival (Table 3).

\section{Discussion}

In the present study, $4 \%$ of the patients with cultureconfirmed pulmonary TB in Taiwan presented with clinical and radiographic manifestations similar to severe CAP that required intensive care support. The interval between ICU admissions and start of anti-TB treatment was about 3 weeks on average. The 100-day mortality for such patients was as high as $52 \%$ (40/77). While the severity of pneumonia on presentation and bacteremia during the ICU stay had an adverse effect on survival, empirical use of FQs may improve survival.
The finding of a high mortality rate in TB patients presenting as severe CAP requiring intensive care is consistent with that of a previous study [32] - which had similar characteristics of the study population, including old age, presence of underlying diseases, malnutrition, and lack of anti-TB treatment within 14 days of the initial visit. The causes for such high mortality rates may be delays in diagnosis and in the timely initiation of appropriate anti-TB therapy. As shown in this study, most of the patients were older people, with a mean age of 72 years, and had multiple co-morbidities. Consideration of other competing bacterial etiologies for pneumonia may cause delays, on top of concerns regarding the adverse effects of empirical initiation of anti-TB therapy before conventional approaches to the 
Table 2 Treatment course and outcome in the fluoroquinolone and nonfluoroquinolone groups

\begin{tabular}{llll}
\hline & Fluoroquinolone $(\boldsymbol{n}=\mathbf{4 3})$ & Nonfluoroquinolone $(\boldsymbol{n}=\mathbf{3 4 )}$ & $\boldsymbol{P}$ value \\
\hline ICU admission to TB study (days) & $1.7 \pm 5.9$ & $5.6 \pm 15.1$ & 0.13 \\
TB study in the ICU within 1 week & $39(91)$ & $28(82)$ & 0.46 \\
Died before ATT was begun & $4(9)$ & $9(27)$ & 0.05 \\
Initiation of ATT in the ICU within 2 weeks & $11(29)$ & $7(29)$ & $>0.99$ \\
Length of ICU stay (days) & $30.0 \pm 20.5$ & $17.5 \pm 17.9$ & $<0.01$ \\
$\quad 27.0 \pm 18.0$ & $31.0 \pm 21.6$ & $22.0 \pm 25.0$ & 0.27 \\
$\quad$ Nonsurvivors in the ICU & $38.6 \pm 61.5$ & $16.0 \pm 14.0$ & 0.03 \\
Intubation period (days) & $28.0 \pm 18.35$ & $19.5 \pm 24.0$ & 0.09 \\
$\quad$ Nonsurvivors in the ICU & $43.0 \pm 71.5$ & $25.0 \pm 29.2$ & 0.13 \\
$\quad$ Survivors in the ICU & $71.2 \pm 62.7$ & $16.9 \pm 21.4$ & $<0.01$ \\
Length of hospital stay(days) & $42.0 \pm 28.0$ & $38.4 \pm 25.5$ & $<0.01$ \\
$\quad$ Nonsurvivors in the hospital & $81.0 \pm 63.3$ & $37.0 \pm 26.41$ & 0.83 \\
$\quad$ Survivors in the hospital & $17(40)$ & $40.0 \pm 25.4$ & $<0.01$ \\
100-day mortality rate & 23 & 0.02 \\
\hline
\end{tabular}

Data presented as $n(\%)$ or mean \pm standard deviation. ATT, anti-tuberculosis treatment; TB, tuberculosis.

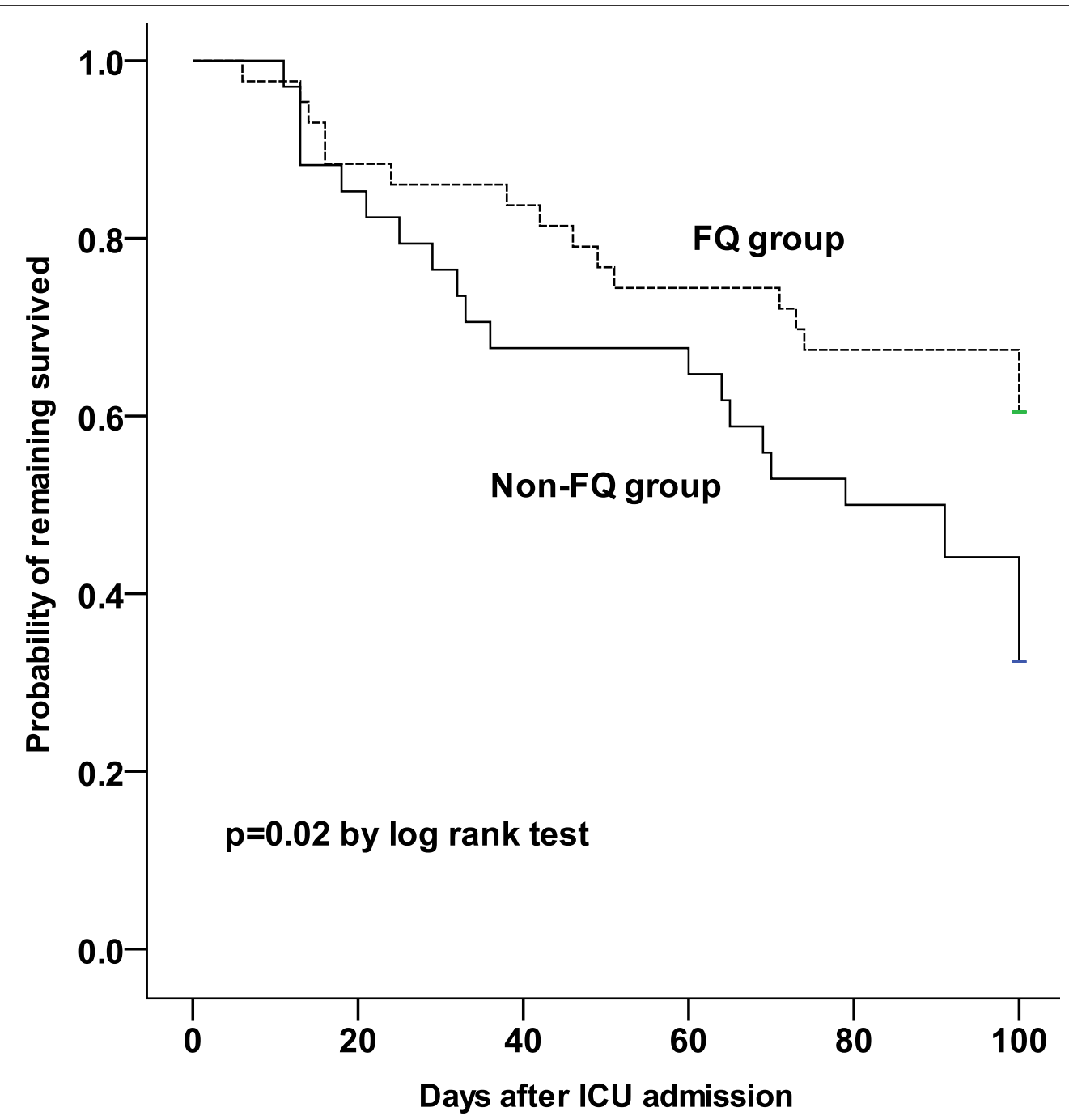

Figure 1 Kaplan-Meier 100-day survival curves for patients in the fluoroquinolone and non-fluoroquinolone groups. The fluoroquinolone (FQ) and non-FQ groups were compared using the log-rank test. 
Table 3 Independent factors associated with 100-day survival, by multivariate Cox proportional hazards regression analysis

\begin{tabular}{|c|c|c|c|c|c|c|}
\hline & Patients (n) & $\begin{array}{l}\text { Mortality within } \\
100 \text { days, } n(\%)\end{array}$ & $\begin{array}{l}\text { Median survival of } \\
\text { fatal cases (days) }\end{array}$ & $P$ value & Hazards ratio & $\begin{array}{l}95 \% \text { confidence } \\
\text { interval }\end{array}$ \\
\hline \multicolumn{7}{|l|}{$\overline{\text { Age }}$} \\
\hline$\geq 70$ & 60 & $34(56.7)$ & 50 & 0.32 & 1.75 & 0.58 to 5.31 \\
\hline$<70$ & 17 & $6(35.3)$ & 16 & & & \\
\hline \multicolumn{7}{|l|}{ APACHE score } \\
\hline$\geq 20$ & 52 & $33(63.5)$ & 36 & 0.01 & 3.75 & 1.34 to 10.44 \\
\hline$<20$ & 25 & $7(28.0)$ & 100 & & & \\
\hline \multicolumn{7}{|l|}{ SOFA score } \\
\hline$\geq 8$ & 35 & $19(54.3)$ & 44 & 0.21 & 1.63 & 0.76 to 3.49 \\
\hline$<8$ & 41 & $20(48.8)$ & 100 & & & \\
\hline \multicolumn{7}{|l|}{ Empiric antibiotic } \\
\hline Fluoroquinolone & 43 & $17(39.5)$ & 46 & $<0.01$ & 0.36 & 0.17 to 0.77 \\
\hline Nonfluoroquinolone & 34 & $23(67.6)$ & 60 & & & \\
\hline \multicolumn{7}{|l|}{ Bacteremia in the ICU } \\
\hline Yes & 11 & $9(81.8)$ & 46 & $<0.01$ & 3.88 & 1.64 to 9.19 \\
\hline No & 66 & $31(47.0)$ & 49 & & & \\
\hline \multicolumn{7}{|c|}{ TB study in the ICU within 1 week } \\
\hline Yes & 67 & $36(53.7)$ & 47.5 & 0.22 & 1.99 & 0.66 to 5.99 \\
\hline No & 10 & $4(40.0)$ & 48.5 & & & \\
\hline \multicolumn{7}{|c|}{ Initiation of ATT in ICU within 2 weeks } \\
\hline Yes & 18 & $10(55.6)$ & 68.5 & 0.53 & 1.38 & 0.50 to 3.84 \\
\hline No & 44 & $17(38.6)$ & 40 & & & \\
\hline
\end{tabular}

APACHE, Acute Physiology and Chronic Health Evaluation score; ATT, anti-tuberculosis treatment; SOFA, Sequential Organ Failure Assessment score; TB, tuberculosis.

diagnosis of pulmonary TB are completed to provide guidance.

FQs are broad-spectrum antimicrobial agents recommended for patients with severe CAP requiring ICU admission [2]. Despite concerns that empirical use of FQs for severe CAP may be associated with delayed diagnosis and treatment of pulmonary TB $[11,33]$, the findings in this study suggest that empirical use of FQs may actually improve the prognosis of TB patients presenting as severe CAP that require intensive care. Aside from benefits of activity against common bacteria that cause severe CAP in older people, FQs in this special condition may also provide survival benefit by rapidly reducing the mycobacterial load [34,35]. In this study, $65 \%$ of patients in the FQ group had sputum culture conversion after FQ monotherapy. Although more prospective studies with larger sample sizes are warranted to confirm the findings here, the results suggest that the delay in diagnosis of active pulmonary $\mathrm{TB}$ and the timely initiation of anti-TB therapy may be prevented in TB endemic areas if investigations for pulmonary TB are routinely performed for patients with severe CAP.

$\beta$-Lactams such as amoxicillin/clavulanate may also have antibacterial activity against $M$. tuberculosis [36]. A population-based cohort study in Canada between 1997 and 2006 reported that previous treatments with any antibiotics, not only FQ, are associated with delayed TB diagnosis [37]. Use of $\beta$-lactams is probably not a confounding factor in the survival analysis, however, because all of the patients in this study received $\beta$-lactams on admission. There is no significant difference in the proportion of patients who received $\beta$-lactam antibiotics. Moreover, there is no significant difference in the intervals from the time of pulmonary TB investigation or from ICU admission to the start of anti-TB therapy between the FQ and non-FQ groups.

The findings of APACHE score $\geq 20$ and bacteremia during the ICU stay as poor prognostic factors are consistent with those of previous studies [28,38]. Nearly $80 \%$ of patients belong to the older age group, which may preclude identifying age $\geq 70$ years as an independent risk factor in this study. In contrast to previous reports $[11,21,22]$, initiation of standard anti-TB therapy within 2 weeks of ICU admission has no consistent significant impact on survival. This is probably due to the small case number in this study and due to less than one-third of the patients being treated early after admission to the ICU.

This study has several limitations such that interpretation of the results should be made with caution. First, 
this is a retrospective study and biases and missing data are unavoidable. For example, HIV sero-status and the cause of death are unknown in 43 and eight patients in the FQ and non-FQ groups, respectively. However, this may not be such a serious concern because HIV prevalence in the general population $(<0.1 \%)$ and in patients with TB $(<1 \%)$ remains low in Taiwan [39]. None of the patients with unknown HIV sero-status developed AIDSdefining illness during follow-up. Second, the study was conducted on older patients with clinical presentations of severe CAP in a medical center. The results may not be applicable to all patients with pulmonary TB that do not require critical care. Third, conventional diagnostic tests for TB (acid-fast smears and culture) are used in this study and, as such, appropriate anti-TB therapy was not initiated in the patients until 3 weeks into their hospital stay. The impact of molecular technology on facilitating rapid $\mathrm{TB}$ diagnosis in this clinical setting warrants further studies. Fourth, the case number of pulmonary TB mimicking severe CAP remains small so the number of M. tuberculosis isolates submitted for drug susceptibility tests obtained during FQ treatment is also small. The risk for emergence of acquired resistance to FQs cannot thus be adequately evaluated. Lastly, despite efforts to adjust for the confounding effects of disease severity and organ dysfunction, the decision of choosing empiric therapy in the face of severe CAP may be based on other factors (for example, drug allergy, toxicity profile, and previous medication history) that are not included in the statistical model.

\section{Conclusion}

Empirical use of FQs may improve survival of patients admitted to the ICU for pulmonary TB mimicking severe CAP.

\section{Key messages}

- Four percent of the patients with culture-confirmed pulmonary $\mathrm{TB}$ in Taiwan present as severe CAP requiring intensive care.

- The mortality rate is high in TB patients presenting as severe CAP requiring intensive care.

- Empirical use of FQs may improve survival for TB patients presenting as severe CAP requiring intensive care.

\section{Abbreviations}

APACHE: Acute Physiology and Chronic Health Evaluation; CAP: communityacquired pneumonia; FQ: fluoroquinolone; TB: tuberculosis.

\section{Author details}

'Department of Traumatology, National Taiwan University Hospital and National Taiwan University College of Medicine, No. 7, Chung Shan S. Road, Zhongzheng District, Taipei City 10002, Taiwan. ${ }^{2}$ Department of Internal Medicine, National Taiwan University Hospital and National Taiwan University College of Medicine, No. 7, Chung Shan S. Road, Zhongzheng District, Taipei City 10002, Taiwan.

\section{Authors' contributions}

$\mathrm{Y}-\mathrm{TT}$ reviewed the medical records, analyzed and interpreted the data, and drafted the manuscript. C- $-\mathrm{CH}, \mathrm{Y}-\mathrm{CC}, \mathrm{C}-\mathrm{CS}$, and $\mathrm{C}-\mathrm{CH}$, analyzed and interpreted the data, and drafted the manuscript. C-FH reviewed the medical records. J-YW designed and oversaw the study, analyzed and interpreted the data, and revised the manuscript. All authors read and approved the manuscript for publication.

\section{Competing interests}

The authors declare that they have no competing interests.

Received: 8 July 2012 Revised: 10 September 2012

Accepted: 22 October 2012 Published: 25 October 2012

\section{References}

1. Marti C, Garin N, Grosgurin O, Poncet A, Combescure C, Carballo S, Perrier A: Prediction of severe community-acquired pneumonia: a systematic review and meta-analysis. Crit Care 2012, 16:R141.

2. Mandell LA, Wunderink RG, Anzueto A, Bartlett JG, Campbell GD, Dean NC, Dowell SF, File TM Jr, Musher DM, Niederman MS, Torres A, Whitney CG: Infectious Diseases Society of America/American Thoracic Society consensus guidelines on the management of community-acquired pneumonia in adults. Clin Infect Dis 2007, 44:S27-S72.

3. Frei CR, Labreche MJ, Attridge RT: Fluoroquinolones in communityacquired pneumonia: guide to selection and appropriate use. Drugs 2011, 71:757-770.

4. Watkins RR, Lemonovich TL: Diagnosis and management of communityacquired pneumonia in adults. Am Fam Physician 2011, 83:1299-1306.

5. Scott JA, Hall AJ, Muyodi C, Lowe B, Ross M, Chohan B, Mandaliya K, Getambu E, Gleeson F, Drobniewski F, Marsh K: Aetiology, outcome, and risk factors for mortality among adults with acute pneumonia in Kenya. Lancet 2000, 355:1225-1230.

6. Liam CK, Pang YK, Poosparajah S: Pulmonary tuberculosis presenting as community-acquired pneumonia. Respirology 2006, 11:786-792.

7. Cremades R, Rodriquez JC, Garcia-Pachón E, Galiana A, Ruiz-García M, López P, Royo G: Comparison of the bactericidal activity of various fluoroquinolones against Mycobacterium tuberculosis in an in vitro experimental model. J Antimicrob Chemother 2011, 66:2281-2283.

8. Yew WW, Chan CK, Chau CH, Tam CM, Leung CC, Wong PC, Lee J: Outcome of patients with multi-drug-resistant pulmonary tuberculosis treated with ofloxacin/levofloxacin-containing regimens. Chest 2000, 117:744-751.

9. Ziganshina LE, Squire SB: Fluoroquinolones for treating tuberculosis. Cochrane Database Syst Rev 2008, 1:CD004795.

10. Dooley KE, Golub J, Goes FS, Merz WG, Sterling TR: Empiric treatment of community-acquired pneumonia with fluoroquinolones, and delays in the treatment of tuberculosis. Clin Infect Dis 2002, 34:1607-112.

11. Wang JY, Hsueh PR, Jan IS, Lee LN, Liaw YS, Yang PC, Luh KT: Empirical treatment with a fluoroquinolone delays the treatment for tuberculosis and is associated with a poor prognosis in endemic areas. Thorax 2006, 61:903-908.

12. Devasia RA, Blackman A, Gebretsadik T, Griffin M, Shintani A, May C, Smith T, Hooper N, Maruri F, Warkentin J, Mitchel E, Sterling TR: Fluoroquinolone resistance in Mycobacterium tuberculosis: the effect of duration and timing of fluoroquinolone exposure. Am J Respir Crit Care Med 2009, 180:365-370.

13. Long R, Chong H, Hoeppner V, Shanmuganathan H, KowalewskaGrochowska K, Shandro C, Manfreda J, Senthilselvan A, Elzainy A, Marrie T: Empirical treatment of community-acquired pneumonia and the development of fluoroquinolone-resistant tuberculosis. Clin Infect Dis 2009, 48:1354-1360.

14. Golub JE, Bur S, Cronin WA, Gange S, Sterling TR, Oden B, Baruch N, Comstock GW, Chaisson RE: Impact of empiric antibiotics and chest radiograph on delays in the diagnosis of tuberculosis. Int I Tuberc Lung Dis 2005, 9:392-397.

15. Yoon YS, Lee HJ, Yoon HI, Yoo CG, Kim YW, Han SK, Shim YS, Yim JJ: Impact of fluoroquinolones on the diagnosis of pulmonary tuberculosis initially treated as bacterial pneumonia. Int J Tuberc Lung Dis 2005, 9:1215-1219

16. van den Boogaard J, Semvua HH, van Ingen J, Mwaigwisya S, van der Laan T, van Soolingen D, Kibiki GS, Boeree MJ, Aarnoutse RE: Low rate of 
fluoroquinolone resistance in Mycobacterium tuberculosis isolates from northern Tanzania. J Antimicrob Chemother 2011, 66:1810-1814.

17. Park IN, Hong SB, Oh YM, Lim CM, Lee SD, Lew WJ, Koh Y, Kim WS, Kim DS, Kim WD, Shim TS: Impact of short-term exposure to fluoroquinolones on ofloxacin resistance in HIV-negative patients with tuberculosis. Int $J$ Tuberc Lung Dis 2007, 11:319-324.

18. Wang JY, Lee LN, Lai HC, Wang SK, Jan IS, Yu CJ, Hsueh PR, Yang PC: Fluoroquinolone resistance in Mycobacterium tuberculosis isolates: associated genetic mutations and relationship to antimicrobial exposure. J Antimicrob Chemother 2007, 59:860-865.

19. Wang JY, Lee LN, Hsueh PR: Factors changing the manifestation of pulmonary tuberculosis. Int I Tuberc Lung Dis 2005, 9:777-783.

20. Lee PL, Jerng JS, Chang YL, Chen CF, Hsueh PR, Yu CJ, Yang PC, Luh KT: Patient mortality of active pulmonary tuberculosis requiring mechanical ventilation. Eur Respir J 2003, 22:141-147.

21. Wang JY, Hsueh PR, Jan IS, Lee LN, Liaw YS, Yang PC, Luh KT: The effect of smoking on tuberculosis: different patterns and poorer outcomes. Int J Tuberc Lung Dis 2007, 11:143-149.

22. Wang JY, Hsueh PR, Wang SK, Jan IS, Lee LN, Liaw YS, Yang PC, Luh KT: Disseminated tuberculosis: a 10-year experience in a medical center. Medicine (Baltimore) 2007, 86:39-46.

23. Center for Disease Control of Taiwan: Statistics of Communicable Diseases and Surveillance Report in Taiwan Area, 2009 Taipei, Taiwan: Center for Disease Control; 2009 [http://www2.cdc.gov.tw/public/Data/ 912311651471.pdf].

24. Wang JY, Lee LN, Chou CS, Huang CY, Wang SK, Lai HC, Hsueh PR, Luh KT: Performance assessment of a nested-PCR assay (the RAPID BAP-MTB) and the BD ProbeTec ET system for detection of Mycobacterium tuberculosis in clinical specimens. J Clin Microbiol 2004, 42:4599-4603.

25. Stuck AE, Minder CE, Frey FJ: Risk of infectious complications in patients taking glucocorticosteroids. Rev Infect Dis 1989, 11:954-963.

26. Knaus WA, Draper EA, Wagner DP, Zimmerman JE: APACHE II: a severity of disease classification system. Crit Care Med 1985, 13:818-829.

27. Vincent IL, Moreno R, Takala J, Willatts S, De Mendonça A, Bruining $H$, Reinhart CK, Suter PM, Thijs LG: The SOFA (Sepsis-related Organ Failure Assessment) score to describe organ dysfunction/failure. On behalf of the Working Group on Sepsis-Related Problems of the European Society of Intensive Care Medicine. Intensive Care Med 1996, 22:707-710.

28. Matic I, Titlic M, Dikanovic M, Jurjevic M, Jukic I, Tonkic A: Effects of APACHE II score on mechanical ventilation; prediction and outcome. Acta Anaesthesiol Belg 2007, 58:177-183.

29. Ferreira FL, Bota DP, Bross A, Mélot C, Vincent JL: Serial evaluation of the SOFA score to predict outcome in critically ill patients. JAMA 2001, 286:1754-1758

30. Kim HJ, Lee CH, Shin S, Lee JH, Kim YW, Chung HS, Han SK, Shim YS, Kim DK: The impact of nutritional deficit on mortality of in-patients with pulmonary tuberculosis. Int I Tuberc Lung Dis 2010, 14:79-85.

31. Centers for Disease Control and Prevention. [http://www.cdc.gov/mmwr/ preview/mmwrhtml/rr5710a2.htm].

32. Erbes $R$, Oettel $K$, Raffenberg M, Mauch $H$, Schmidt-loanas M, Lode $H$ : Characteristics and outcome of patients with active pulmonary tuberculosis requiring intensive care. Eur Respir J 2006, 27:1223-1228.

33. Ginsburg AS, Hooper N, Parrish N, Dooley KE, Dorman SE, Booth J, DienerWest M, Merz WG, Bishai WR, Sterling TR: Fluoroquinolone resistance in patients with newly diagnosed tuberculosis. Clin Infect Dis 2003, 37:1448-1452.

34. Johnson JL, Hadad DJ, Boom WH, Daley CL, Peloquin CA, Eisenach KD, Jankus DD, Debanne SM, Charlebois ED, Maciel E, Palaci M, Dietze R: Early and extended early bactericidal activity of levofloxacin, gatifloxacin in pulmonary tuberculosis. Int I Tuberc Lung Dis 2006, 10:605-612.

35. Pletz MWR, De Roux A, Roth A, Neumann KH, Mauch H, Lode H: Early bactericidal activity of moxifloxacin in treatment of pulmonary tuberculosis: a prospective, randomized study. Antimicrob Agents Chemother 2004, 48:780-782.

36. Dinçer I, Ergin A, Kocagöz T: The vitro efficacy of beta-lactam and betalactamase inhibitors against multi-drug resistant clinical strains of Mycobacterium tuberculosis. Int J Antimicrob Agents 2004, 23:408-411.

37. Wang M, Fitzgerald JM, Richardson K, Marra CA, Cook VJ, Hajek J, Elwood RK, Bowie WR, Marra F: Is the delay in diagnosis of pulmonary tuberculosis related to exposure to fluoroquinolones or any antibiotic? Int Tuberc Lung Dis 2011, 15:1062-1068.
38. Nasa P, Juneja D, Singh O, Dang R, Arora V, Saxena S: Incidence of bacteremia at the time of ICU admission and its impact on outcome. Indian J Anaesth 2011, 55:594-598.

39. Yang $\mathrm{CH}$, Huang $\mathrm{YF}$, Wang KF, Chan PC, Chen KJ: Trend of HIV prevalence in Tuberculosis patients in Taiwan, 2001-2008 Poster Presentation at 40th Union World Conference on Lung Health, December 2009 Cancun, Maxico.

doi:10.1186/cc11839

Cite this article as: Tseng et al:: Empirical use of fluoroquinolones improves the survival of critically ill patients with tuberculosis mimicking severe pneumonia. Critical Care 2012 16:R207.

\section{Submit your next manuscript to BioMed Central and take full advantage of:}

- Convenient online submission

- Thorough peer review

- No space constraints or color figure charges

- Immediate publication on acceptance

- Inclusion in PubMed, CAS, Scopus and Google Scholar

- Research which is freely available for redistribution

Submit your manuscript at www.biomedcentral.com/submit
Ciomed Central 